International Journal of Performability Engineering Vol. 13, No. 2, March 2017, pp. 143-152

(C) Totem Publisher, Inc. 4625, Stargazer Dr. Plano,

Printed in U.S.A.

\title{
Simulation and Analysis of an Eddy Current Damper
}

\author{
ISHAN LUTHRA ${ }^{1}$ and S. K. PAHUJA ${ }^{2}$ \\ ${ }^{1}$ Lovely Professional University, Phagwara, Punjab, INDIA \\ ${ }^{2}$ Dr. B.R. Ambedkar National Institute of Technology, Jalandhar, Punjab, INDIA
}

(Received on Nov.25, 2016 and Revised on February 28, 2017)

\begin{abstract}
The applications of eddy current dampers have been explored in the past few decades due to their non-contact nature which poses several advantages over the conventional hydraulic dampers. This paper discusses the real-time simulation and analysis of an eddy current damper which can be used for the protection of windows and doors against winds and human behavior. The damper consists of a hollow cylindrical conductor and axially magnetized permanent magnets. The equations have been solved to obtain the final velocity of the window in LABVIEW. Decrease in final velocity of the window with damper is calculated at different instants and for different forces. Performance of the damper is compared for different conductors also. The damping coefficient, damping ration and loss of radial flux density in the air gap are also calculated. The results show that the damper can be successfully used as an alternative to the hydraulic dampers for safety.
\end{abstract}

Keywords: damper, eddy currents, non-contact, permanent magnets, protection, safety

\section{Introduction}

Safety from harmful effects of different natures has always been one of the priorities of our lives. It becomes imperative to reduce the impact of such harmful effects in order to ensure safety. Reduction in the impact of an event is often referred to as Damping. A damper significantly helps in ensuring safety by draining energy of the system producing undesirable and harmful effects.

Conventional hydraulic dampers have been invariably used in the past to provide damping effect in various applications. These dampers suffer from certain drawbacks including seal breakage, oil leakage and difficult adjustment of damping ratio [2]. Eddy current dampers on the other hand are a potential solution to these problems, because of their non-contact nature. Eddy currents (also known as Foucault currents) were discovered by French physicist Leon Foucault in 1855 when he observed that greater force was required to rotate a copper disc when it was made to rotate between the poles of a magnet [10]. Eddy currents are circular currents which flow in closed loops in planes perpendicular to the magnetic lines of force. These are induced due to change in the strength of magnetic field across the conductor. The magnetic field produced by these eddy currents is such that it always opposes the change in external magnetic field. This force of opposition is proportional to the rate of change of external magnetic field and therefore provides a damping effect similar to that provided by the hydraulic dampers. In more than last two decades, several researchers have explored the use of eddy currents in various fields including damping in automobiles and physical structures, braking, sensing, positioning systems etc. 
Sodano [1] mounted a PM on the tip of an electromagnetic shaker such that the relative motion between the magnet and the conductive structure causes a time changing magnetic field to induce eddy currents in the structure. Saxena and Patel [3] have also theoretically simulated the response of a vibrating cantilever beam in the absence as well as presence of a time changing magnetic field provided by an electromagnet. An electromagnetic vibration absorber was suggested by Liu et al. [16], whose stiffness could be easily adjusted online. Zhihao et al. [2] designed and constructed a large scale TMD based on eddy current damping mechanism. Kienholtz et al. [15] developed many eddy current based TMDs in order to mitigate various vibration modes of a solar array simulator in a frequency range of 0.1-1 Hz. Yang et al. [3] used eddy current damping mechanism to attenuate the vibrations of machine which may cause harm to the tool as well as the work piece. Teshima et al. [11] studied the effect of an ECD on vibrations associated with super conductive levitation system. Matsuzaki et al. [12], [13] proposed an ECD based vibration isolation system in which the vibrations of a partially magnetized cantilever beam were suppressed with the use of electromagnetic forces. Lee et al. [9] developed an eddy current type magnetic floor hinge to be used in doors. Ebrahimi [8] for the first time introduced the eddy current damping mechanism in a hybrid damper in automotive suspension application. Liu et al. [4] introduced the structure and working principle of an eddy current retarder acting as an auxiliary brake set. Varonis and Eda [7] addressed the sensing of torque in machine shafts in a non-contact manner based upon eddy currents. Hu et al. [5] designed a passive permanent magnet eddy current based damper which can be used in a maglev positioning platform.

In this study an eddy current damper has been designed and analysed. The motivation of the study is to ensure safety to windows and doors at homes, offices, educational institutions, hospitals etc. against winds and human behaviour, which may otherwise cause noise and damage to the physical structure.

\section{Choice of Materials}

\subsection{Conductor}

Metals are good conductors and their conductivities are typically of the order of $10 \mathrm{e} 7 \mathrm{~S} / \mathrm{m}$ [17]. In all conductors, the magnitude of electrical conductivity depends on the number of electrons available to participate in the process of conduction which is related to the arrangement of electron levels with respect to energy and the manner in which these levels are occupied by electrons. These electrons are known as free electrons. Metals have good conductivity because of large number of these free electrons. The conductivities of some common metals and alloys at room temperature have been given in Table 1. Copper is the most widely used metallic conductor because of its electrical properties [17]. Silver although having better conductivity than copper is rarely used because of its cost. Another good conductor is Aluminum, which is preferable because of its cheap cost but has conductivity approximately half of that of copper. Also, investigations have revealed that aluminum poses higher fire hazard and risk as compared to copper [17]. Gold also has good conductivity but its high cost restricts its use. Therefore, it can be said that copper is the best choice as a conductor because of its properties and cost effectiveness. 
Table 1: Conductivities of Metals and Alloys at Room Temperature

\begin{tabular}{|c|c|}
\hline Metal/Alloy & Electrical Conductivity (X 10e7 S/m) \\
\hline Silver & 6.8 \\
\hline Copper & 5.96 \\
\hline Gold & 4.3 \\
\hline Aluminum & 3.69 \\
\hline Brass (70Cu-30Zn) & 1.6 \\
\hline Iron & 1.0 \\
\hline Platinum & 0.94 \\
\hline Plain Carbon Steel & 0.6 \\
\hline Stainless Steel & 0.2 \\
\hline
\end{tabular}

\subsection{Magnetic Field}

Magnetic field can be provided either by a permanent magnet or by an electromagnet. Permanent magnets are far better than electromagnets because they have continuously maintained magnetic fields, do not require any external power source to generate magnetic field and do not generate heat during their operation [17].

Hard magnetic materials which have high resistance to demagnetization are used in permanent magnets [17]. Two most important characteristics of these materials are coercivity and the energy product. The value of energy product is a representative of the energy required to demagnetize the magnet i.e. higher is the value of energy product, more difficult it will be to demagnetize the magnet. Permanent magnet materials having energy product value more than $80 \mathrm{~kJ} / \mathrm{m}^{3}$ are known as high-energy hard magnetic materials [17]. Samarium-Cobalt magnets $\left(\mathrm{SmCo}_{5}\right)$ and Neodymium-Iron-Boron magnets $\left(\mathrm{Nd}_{2} \mathrm{Fe}_{14} \mathrm{~B}\right)$ are the commercialized high energy permanent magnets. Properties of these two magnets are given in Table 2.

Samarium is a rare as well as expensive material, also the sources of cobalt are unreliable and its cost is also variable [17]. Also from Table 2 it can be seen that values of remnant flux density, coercivity and energy product are higher for $\mathrm{Nd}_{2} \mathrm{Fe}_{14} \mathrm{~B}$, making them a better choice as compared to $\mathrm{SmCo}_{5}$. Hence for a large number of diverse applications requiring hard magnetic materials, $\mathrm{Nd}_{2} \mathrm{Fe}_{14} \mathrm{~B}$ alloys have become the best choice since 1980s [18]. As $\mathrm{Nd}_{2} \mathrm{Fe}_{14} \mathrm{~B}$ is composed of materials from the lanthanide series in the rare earth group of elements, thus it is also known as a rare earth magnet [18]. Plating of tin, nickel or zinc and epoxy resin coatings are used to provide protection to these rare earth magnets from corrosion [2].

Table 2: Properties of High Energy Hard Magnetic Materials

\begin{tabular}{|l|l|l|l|}
\hline Composition & $\begin{array}{c}\text { Remnant Flux Density } \\
\text { (Tesla) }\end{array}$ & $\begin{array}{c}\text { Coercivity (Amp- } \\
\text { turn/m) }\end{array}$ & $\begin{array}{c}\text { Energy Product } \\
\text { (kJ/m } \mathbf{3} \text { ) }\end{array}$ \\
\hline $\mathrm{SmCo}_{5}$ & 0.92 & 720,000 & 170 \\
\hline $\mathrm{Nd}_{2} \mathrm{Fe}_{14} \mathrm{~B}$ & 1.16 & 848,000 & 255 \\
\hline
\end{tabular}




\section{Methodology}

\subsection{Block Diagram}

When a random input force $\mathrm{F}_{\text {in }}$ acts on mass $\mathrm{M}$ of the window, it results in acceleration of the window. The acceleration is integrated to obtain the velocity of window after a given time. $\mathrm{C}_{\mathrm{d}}$ is the damping coefficient of the eddy current damper, due to which a damping force $F_{d}$ is created to oppose the input force on the window.

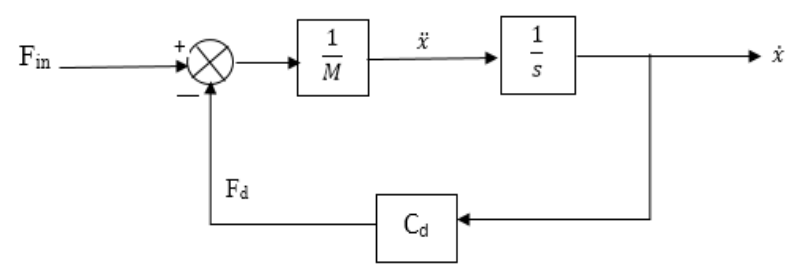

Figure 1: Block Diagram of the System

The final velocity of the window according to the block diagram of the system given in Fig. 1 is obtained as:

$$
\dot{x}=\frac{F_{\text {in }}}{M} e^{-\frac{C_{d}}{M} t}
$$

According to Newton's First law of motion, the velocity of a body with mass M and force $F_{\text {in, }}$, after $\mathrm{t}$ seconds is given by:

$$
\dot{x}_{o}=\frac{F_{\text {in }}}{M} t
$$

Subscript $o$ is used in the expression of velocity in (2) to represent ordinary case, without damper. The initial velocity is assumed zero here.

\subsection{Analytical Model of Damper}

The damper consists of a hollow cylindrical conductor of copper and axially magnetized Neodymium permanent magnets. The black arrows facing each other in Fig. 2 indicate like poles of magnet in proximity. The magnets are separated by iron poles for higher flux linkage with conductor, because of their higher magnetic permeability as compared to air. The magnetic arrangement is mounted on a non-ferromagnetic rod which can be fixed to the window. Dimensions of the damper are given in Table 3.

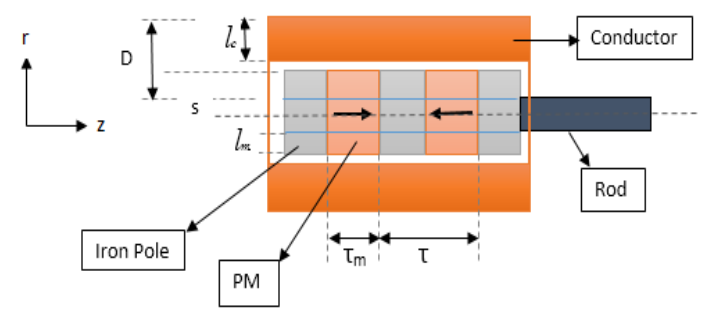

Figure 2: Damper Model [6] 
Spring is not required in such a damper since the stiffness is provided by the force of repulsion between the like magnetic poles in proximity with each other [14]. Axial flux in the iron pole between the two magnets in Fig. 2 is equal but in opposite direction from the magnets and thus the net axial flux will be zero. Therefore, the net flux linking with the conductor surface will be the radial flux from the two magnets and it would be twice in magnitude to the radial flux from each magnet.

Table 3: Dimensions of the Damper

\begin{tabular}{|c|c|}
\hline Dimension & Value (mm) \\
\hline Pole pitch, $\tau$ & 5 \\
\hline Thickness of magnet, $\tau_{\mathrm{m}}$ & 2.75 \\
\hline Radius of magnet, $\mathrm{Rm}=\mathrm{l}_{\mathrm{m}}+\mathrm{s}$ & 6 \\
\hline Radius of rod, $\mathrm{s}$ & 2.5 \\
\hline
\end{tabular}

Accordingly, in such a configuration the net radial flux density from each iron pole surrounded by permanent magnets on both sides is given by Ebrahimi et al. [6] as:

Where,

$$
B_{r}=2\left(B_{r}(r, z)_{l_{m}+s, \tau_{m}}-B_{r}(r, z)_{s, \tau_{m}}\right)
$$

$$
B_{r}(r, z)_{R, \tau_{m}}=\frac{\mu_{o} I}{2 \pi \tau_{m}} \int_{-\tau_{m} / 2}^{+\tau_{m} / 2} \frac{\left(z-z^{\prime}\right)}{r\left[(R+r)^{2}+\left(z-z^{\prime}\right)^{2}\right]^{1 / 2}} X\left[-K(k)+\frac{R^{2}+r^{2}+\left(z-z^{\prime}\right)^{2}}{(R-r)^{2}+\left(z-z^{\prime}\right)^{2}} E(k)\right] d z^{\prime}
$$

Here, $K(k)$ and $E(k)$ are complete elliptical integrals of the first and second kind, respectively and they are defined as: $K(k)=\int_{0}^{\pi / 2} \frac{d \theta}{\sqrt{\left(1-k \sin ^{2} \theta\right)}}, E(k)=\int_{0}^{\pi / 2} \sqrt{1-k \sin ^{2} \theta}$ and $k=4 R r\left[(R+r)^{2}+\left(z-z^{\prime}\right)^{2}\right]^{-1}$

$R$ and $\tau_{\mathrm{m}}$ represent the radius and length of the permanent magnets, respectively. $I$ is the equivalent current of the PM and is equal to $M \tau_{\mathrm{m}}$ [19], where $\mathrm{M}$ represents the constant magnetization of the PM. Since (4) cannot be solved analytically, therefore a numerical method is required to solve the equation. Since, alternating eddy currents will be induced in the conductor, therefore another important factor of consideration is the skin effect. Due to skin effect, the eddy current density at the surface of conductor will be higher than that at the core of the conductor. Skin effect also causes an increase in resistance of the conductor due to increase in frequency. If $I_{\mathrm{S}}$ is the current at the surface of conductor and $\delta_{\mathrm{p}}$ the penetration depth, then the exponential decrease in the eddy current density with depth $\mathrm{d}_{\mathrm{s}}$ from conductor surface is given by:

$$
J=I_{s} e^{-d_{s} / \delta_{p}}
$$

Penetration depth, $\delta_{\mathrm{p}}$ is the depth below the surface of conductor where the current density decreases to $1 / \mathrm{e}$ of the current at surface.

$$
\delta_{p}=\sqrt{\frac{1}{\pi \sigma \mu_{a} \omega}}
$$

where, $\mu_{\mathrm{a}}$ is the absolute permeability of conductor, $\omega$ is the frequency of alternating eddy current and $\sigma$ is the conductivity of conductor. 
The mass, $M$ and stiffness, $\mathrm{K}$ of the system are considered as $4 \mathrm{~kg}$ and $6 \mathrm{KN} / \mathrm{m}$, respectively. Therefore, the natural frequency, $\omega_{\mathrm{n}}$ of the system is computed as $38.72 \mathrm{rad} / \mathrm{s}$ or $6.16 \mathrm{~Hz}$ using the following relation:

$$
\omega_{n}=\sqrt{\frac{K}{M}}
$$

Damping coefficient, $\mathrm{C}_{\mathrm{d}}$ used in (1) is expressed as [8]:

$$
C_{d}=2 \pi \sigma\left(\tau-\tau_{m}\right) \int_{r_{\text {in }}}^{r_{\text {out }}} r B_{r}^{2} e^{\frac{-\left(r-r_{\text {in }}\right)}{\delta p}} d r
$$

$r_{\text {in }}$ and $r_{\text {out }}$ indicate the inside and outside radius of the conductor tube. Damping ratio, $\xi$ of the proposed damper at natural frequency is obtained using the relation:

$$
\xi=\frac{C_{d}}{2 M \omega_{n}}
$$

Table 4: Properties of Conductors and Permanent Magnet

\begin{tabular}{|c|c|}
\hline Property & Value \\
\hline Conductivity of copper & $5.96 \mathrm{e} 7 \mathrm{~S} / \mathrm{m}$ \\
\hline Conductivity of aluminum & $3.69 \mathrm{e} 7 \mathrm{~S} / \mathrm{m}$ \\
\hline Absolute permeability of conductors & $1.2566 \mathrm{e}-6$ \\
\hline Type of magnet & Nd-Fe-B Grade 42 \\
\hline Remnant flux density of magnet & $1.17 \mathrm{~T}$ \\
\hline Constant magnetization of magnet, $M$ & $1.03 \mathrm{e} 6 \mathrm{~A} / \mathrm{m}$ \\
\hline
\end{tabular}

Since the performance of the damper has also been computed for aluminum conductor in this paper, therefore some important properties of the conductors and permanent magnet are provided in Table 4.

\subsection{Schematic Arrangement of Damper}

Figure 3 shows the schematic arrangement of the damper on the window or door. Though the door has rotational motion but the damper is arranged to have a linear motion on the surface of door. A wheel track is fixed on the door, on which the wheel is free to move with the rotatory movement of door. The magnet-iron arrangement mounted over a nonferromagnetic rod is fixed over the link driving the wheel. The link is further coupled to

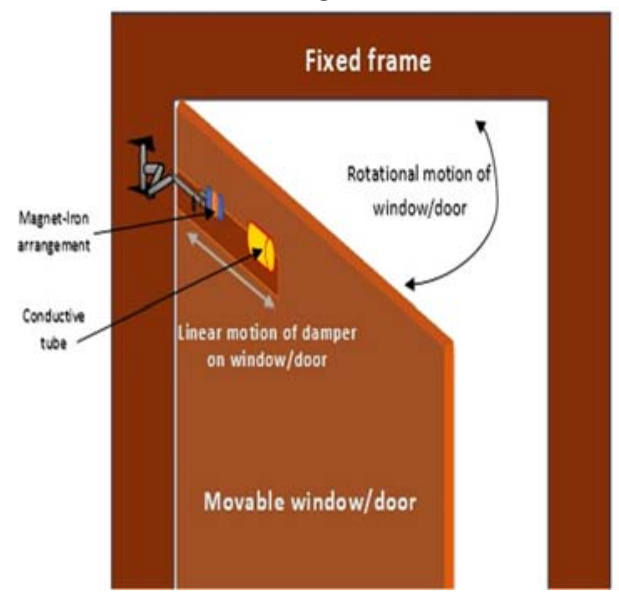

Figure 3: Schematic Arrangement of Damper 
elbow joints connected to the fixed frame, so that closure of the door drives the wheel and in turn causes movement of magnet-iron arrangement into the conductive tube. Therefore, the performance of the damper in next section has been analyzed considering its linear motion as per the schematic arrangement.

\subsection{Energy Transfer in the System}

The magnetic field with respect to conductor changes due to the kinetic energy of wind transferred to the window. This causes the eddy currents to induce in the conductor. Due to the resistance of conductor, heat is generated in it in the form of $I^{2} R$ and dissipated to the environment. Thus, the kinetic energy is converted to electrical energy which is further converted to heat energy. The dissipation of heat in the surroundings implies the dissipation of the kinetic energy of window.

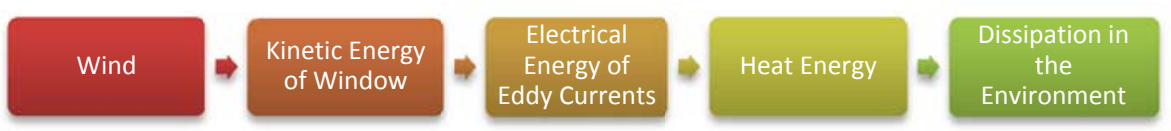

Figure 4: Flow of Energy in the System

\section{Results and Discussions}

\subsection{Final Velocity at Different Instants}

The final velocity of the window has been computed with and without damper at different instants. The mass and input force of the system are considered as $4 \mathrm{~kg}$ and $10 \mathrm{~N}$, respectively. It can be seen from Fig. 5 that with increase in time the final velocity with damper decreases whereas that without damper increases. This is due to the exponential nature of the expression of final velocity given in (1) and its linear nature as given in (2).

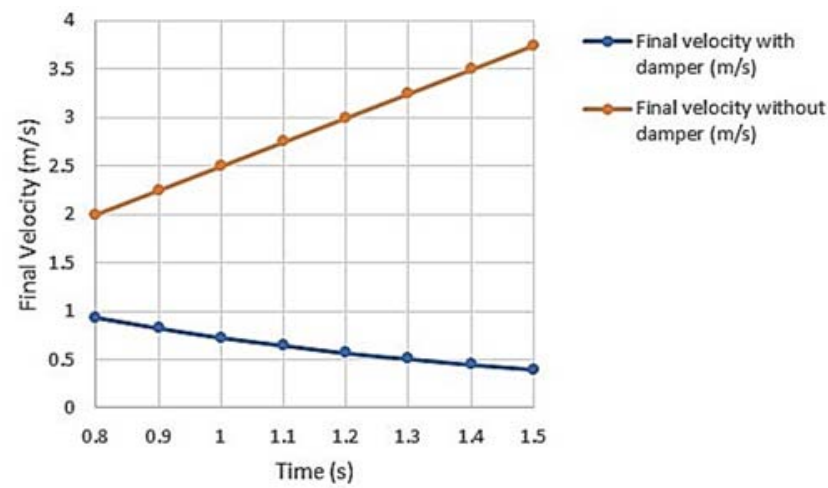

Figure 5: Final Velocity of Window

Observation time of $0.8 \mathrm{~s}$ to $1.5 \mathrm{~s}$ has been chosen in this study as per personal observation and approximation of the time taken by a window to close due to wind. A decrease of $52.84 \%$ to $89.28 \%$, as shown in Fig. 6 , has been achieved in the final velocity of the window with damper.

\subsection{Final Velocity for Different Input Forces}

Final velocity of window with and without damper has been calculated for different random input forces on a 4-kg mass, after $0.8 \mathrm{~s}$. From the results shown in Fig. 7, it can be 
seen that the percentage decrease in final velocity of the damper at a given instant remains the same, irrespective of the applied force.

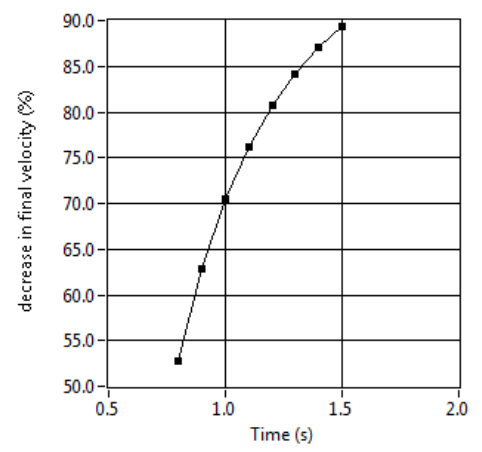

Figure 6: Percentage Decrease in Final Velocity with Damper

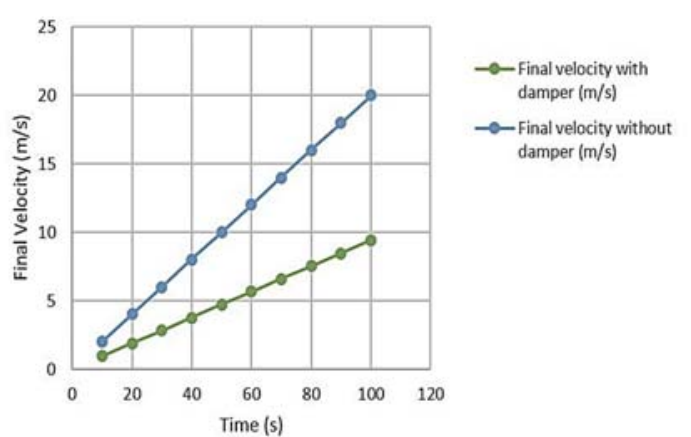

Figure 7: Final Velocity with Damper vs. Input Force

\subsection{Damper Performance for Different Conductors}

The percentage decrease in final velocity at different instants using damper with copper tube has been compared with that using aluminium tube of same dimensions and the results have been plotted in Fig. 8. It can be seen that percentage decrease in final velocity using copper tube in damper is in the range of $52.84 \%$ to $89.28 \%$ from $0.8 \mathrm{~s}$ to $1.5 \mathrm{~s}$, whereas using aluminium tube there is $34.24 \%$ to $80 \%$ decrease in the final velocity during the same period. This means copper tube gives better performance in the damper as compared to aluminium tube and this is due to higher conductivity of copper. Due to higher conductivity of copper, larger eddy currents are setup in it and result in greater force of opposition to the change in external magnetic field.

\subsection{Change in Radial Flux Density}

The density of radial flux which induces eddy currents in the proposed design is also calculated in the air gap between surface of conductor and that of iron pole and this change is shown in Fig. 9. The radial flux density decreases from $0.422 \mathrm{~T}$ at the surface of iron pole to $0.371 \mathrm{~T}$ at the surface of conductor. There is only $12.32 \%$ decrease in the radial flux density and therefore it can be said that most of the flux links with the conductor. The density of radial flux which induces eddy currents in the proposed design is also calculated in the air gap between surface of conductor and that of iron pole and this change is shown in Fig. 9. The radial flux density decreases from $0.422 \mathrm{~T}$ at the surface of iron pole to $0.371 \mathrm{~T}$ at the surface of conductor. There is only $12.32 \%$ decrease in the radial flux density and therefore it can be said that most of the flux links with the conductor.

\section{Conclusions}

In this study, an eddy current damper was simulated and analyzed. The application in focus was to ensure the safety of windows and doors against winds and human behavior. Instead of flat permanent magnet and conductor, annular shaped permanent magnets were used and tubular design was chosen for the conductor, to reduce the leakage flux. Iron poles were used with permanent magnets to increase the linkage of flux with the 
conductor. Copper conductor was used because of its high conductivity, easy availability and less hazardous nature.

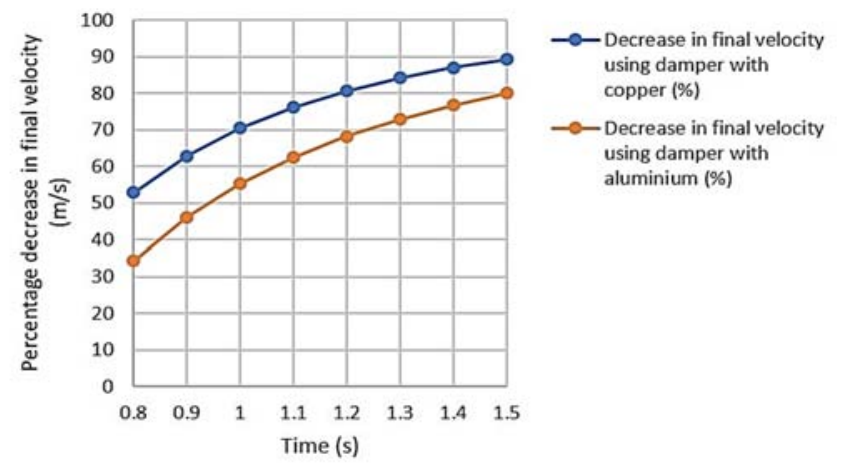

Figure 8: Decrease in Final Velocity with Damper using Different Conductors

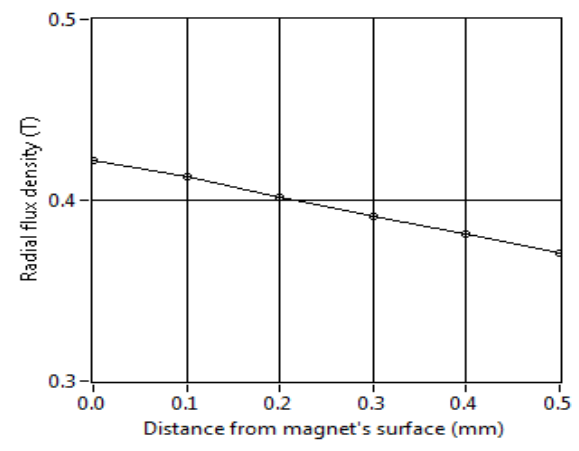

Figure 9: Change in Radial Flux Density

Neodymium type permanent magnets were used because of their high coercivity, high value of energy product and comparatively lower cost. This means that the damper is durable and economical. By placing like magnetic poles in proximity with each other, the requirement of spring was fulfilled. It was observed that most of the flux produced by the magnets linked with the conductor and there was only $12.32 \%$ loss of radial flux density in the air gap. A significant decrease of up to $90 \%$ was seen in the final velocity of window with the use of damper. Decrease in the final velocity with damper was seen to be higher with the use of copper conductor as compared to aluminum conductor. It was also observed that the percentage decrease in the final velocity with damper at a given instant remained constant irrespective of the input force. This indicates that the damper is reliable under different atmospheric conditions. Damping coefficient of the damper was found to be $4.87 \mathrm{~kg} / \mathrm{s}$. A damping ratio of 0.015 is obtained at natural frequency. Apparently, the damper performs well but low damping ration needs further investigation, which will be taken by the authors in their future study.

\section{Acknowledgement}

Authors would like to thank the anonymous referees who helped to improve the paper. 


\section{References}

[1]. Sodano H.A. Non-Contact Eddy Current Excitation Method for Vibration Testing. Exp Mech, 2006;46(5): 627-635.

[2]. Zhihao W, Zhengqing C, Jianhui W. Feasibility Study of a Large Scale Tuned Mass Damper with Eddy Current Damping Mechanism. Earthq Eng \& Eng Vib, 2012;11(3): 391-401.

[3]. Saxena A, Patel R.K. Vibration Control of Cantilever Beam Using Eddy Current Damper. Int J Eng Sci Inn Tech, 2013;2(3): 432-439.

[4]. Liu C.Y, Jiang K.J, Zhang Y. Design and Use of an Eddy Current Retarder in an Automobile. Int J Auto Tech, 2011;12(4): 611-616.

[5]. Hu X.I.E, Shuyuan M.A, Wenbin L.I. The Electromagnetic Analysis and Design of a New Permanent Magnet Eddy Current Damper. Int Multi Conf of Eng and Comp Sci, Hong Kong, March 12-14, 2014.

[6]. Ebrahimi B, Khamesee M.B, Golnaraghi F. Permanent Magnet Configuration in Design of an Eddy Current Damper. Microsyst Tech, 2010;16(3): 19-24.

[7]. Varonis O.J, Ida N. Eddy Current Sensing of Torque in Rotating Shafts. Sens Imaging, 2013;14(3): 81-92.

[8]. Ebrahimi B. Development of Hybrid Electromagnetic Dampers for Vehicle Suspension System. Ph.D. Thesis, University of Waterloo, Department of Mechanical Engineering, 2009.

[9]. Lee K, Kim C, Park K. Development of an Eddy Current Type Magnetic Floor Hinge. IEEE Trans Indus Elect, 2006;53(2): 561-568.

[10]. https://en.wikipedia.org/wiki/Eddy_current

[11]. Teshima H, Tanaka M, Miyamoto K, Nohguchi K, Hinata K. Vibrational Properties in Superconducting Levitation Using Melt-Processed Ybacuo Bulk Superconductors. Physica C, 1996;256(1-2): 142-148.

[12]. Matsuzaki Y, Ishikubo D, Kamita T, Ikeda T. Vibration Control System Using Electromagnetic Forces. J Intel Material Sys Struct, 1997;8(3): 751-756.

[13]. Matsuzaki Y, Ikeda T, Nae A, Sasaki T. Electromagnetic Forces for a New Vibration Control System: Experimental Verification. Smart Mater Struct, 2000;9(2): 127-131.

[14]. Kwag D.G, Bae J.S, Hwang J.H. Experimental Study for Dynamic Characteristics of an Eddy Current Shock Absorber. J KSAS, 2007;35(12): 1089-1094.

[15]. Kienholz D.A, Pendleton S.C, Richards K.E, Morgenthaler D.R. Demonstration of Solar Array Vibration Suppression. Smart Struct Mater, 1994;2193(59): 59-72.

[16]. Liu J, Liu K. A Tunable Electromagnetic Vibration Absorber: Characterization and Application. J Sound Vibr, 2006;295(3-5): 708-724.

[17]. Callister, W.D, Rethwisch, D.G. Materials Science and Engineering: An Introduction. (8th ed.). Wiley, USA, 2009.

[18]. Jensen, J, Mackintosh, A.R. Rare Earth Magnetism: Structures and Excitation. (1st ed.). Clarendon Press, Oxford, 1991.

[19]. Furlani, E.P. Permanent Magnet and Electromechanical Devices. (1 $1^{\text {st }}$ ed.). Academic Press, London, 2001.

Ishan Luthra is Post Graduate in Control and Instrumentation Engineering from Dr. B.R. Ambedkar National Institute of Technology, Jalandhar, India. He is currently Assistant Professor in the Department of Electronics and Communication Engineering, Lovely Professional University, Phagwara, India.

S.K. Pahuja is Associate Professor in the Department of Instrumentation and Control Engineering, Dr. B.R. Ambedkar National Institute of Technology, Jalandhar, India. 